\title{
SMALL-SCALE VARIABILITY IN THE COASTAL ATMOSPHERIC BOUNDARY LAYER
}

\author{
BRANKO GRISOGONO*, LINDA STRÖM and MICHAEL TJERNSTRÖM \\ Department of Meteorology, Uppsala University, Uppsala, Sweden
}

(Received in final form, 5 January, 1998)

\begin{abstract}
The influence of the main large-scale wind directions on thermally driven mesoscale circulations at the Baltic southwest coast, southeast of Sweden, is examined. The aim of the study is to highlight small-scale alterations in the coastal atmospheric boundary layer. A numerical threedimensional mesoscale model is used in this study, which is focused on an overall behaviour of the coastal jets, drainage flows, sea breezes, and a low-level eddy-type flow in particular. It is shown that synoptic conditions, together with the moderate terrain of the southeast of Sweden (max. height $h_{0} \leq$ $206 \mathrm{~m}$ ), governs the coastal mesoscale dynamics triggered by the land-sea temperature difference $\Delta T$. The subtle nature of coastal low-level jets and sea breezes is revealed; their patterns are dictated by the interplay between synoptic airflow, coastline orientation, and $\Delta T$.

The simulations show that coastal jets typically occur during nighttime and vary in height, intensity and position with respect to the coast; they interact with downslope flows and the background wind. For the assigned land surface temperature (varying $\pm 8 \mathrm{~K}$ from the sea temperature) and the opposing constant geostrophic wind $8 \mathrm{~m} \mathrm{~s}^{-1}$, the drainage flow is more robust to the opposing ambient flow than the sea breeze later on. Depending on the part of the coast under consideration, and the prevailing ambient wind, the sea breeze can be suppressed or enhanced, stationary at the coast or rapidly penetrating inland, locked up in phase with another dynamic system or almost independently self-evolving. A low-level eddy structure is analyzed. It is governed by 'tilting', 'divergence' and horizontal advection terms. The horizontal extent of the coastal effects agrees roughly with the Rossby radius of deformation.
\end{abstract}

Keywords: Coastal jet, Marine atmospheric boundary layer, Mesoscale eddy, Sea breeze

\section{Introduction}

\subsection{EVIDENCE OF BOUNDARY-LAYER VARIABILITY}

The coastal marine atmospheric boundary layer (MABL) appears to be far from horizontally homogeneous and isotropic. Winant et al. (1988) reveal significant spatial variability of the MABL at the northern Californian coast during different synoptic conditions. Their experimental study indicates that the MABL can vary over short horizontal distances that scale with $L \leq 50 \mathrm{~km}$. Wilczak et al. (1991) use state-of-the-art observations and numerical modeling to study a variety

* On leave from University of Zagreb, Croatia.

The corresponding author address: B. Grisogono, Dept. of Meteorology, Stockholm Univ., Arrheniuslab. S-10691, Stockholm, Sweden. Email: branko@misu.su.se

Boundary-Layer Meteorology 88: 23-46, 1998.

(C) 1998 Kluwer Academic Publishers. Printed in the Netherlands. 
of mesoscale features such as vortices, sea breezes upslope- and downslope winds in the Santa Barbara coastal region. The MABL's variability found in their study scales with $L \sim 20 \mathrm{~km}$ and a noticeable timescale is somewhat longer than one hour. Similar conclusions can be drawn from a numerical study by Kessler and Douglas (1991). These analyses also indicate the importance of three-dimensional (3D) effects in the coastal flows. Observations of sea breezes in other areas show considerable 3D structure of the sea breeze (Holland and McBridge, 1989); this is also in qualitative agreement with numerical simulations by Arritt (1989) who, in addition, finds a general consistency with the linear theory of Rotunno (1983). Tjernström (1991), Banta et al. (1993) and Finkele et al. (1995) reveal small-scale variability within the sea breeze flows with $L \leq 10 \mathrm{~km}$. Banta et al. (1993) refer to an apparent disagreement between measurements and linear theories. They find no evidence of a compensatory return flow, and the related discrepancy between the observed and derived aspect ratios, $\delta$ (horizontal versus vertical extent) for the sea breeze. As an explanation, they propose a mass compensation outside of the sea breeze that is introduced by the inland terrain; thus, the mass divergence above the sea-breeze front required in simpler models could be attained within a coupling between the sea breeze, and circulations due to valleys and mountains. Brümmer et al. (1995) show an example of an interaction between a synoptic and a sea-breeze front at the North Sea in which the former became notably intensified in the ABL. The same case is simulated by Rhodin (1995) who highlights the importance of fine-scale model resolution to verify the small-scale variability.

Inhomogeneous, time-dependent coastal flows are found in the Baltic area too. Smedman et al. (1993) analyze turbulence budgets of the coastal jets that generally appear due to an inertial oscillation related to warm air flowing out over cold water yielding a frictional decoupling. In the absence of baroclinicity, most of the data presented are interpreted in terms of 'self-preservation' valid for laboratory shearfree flows. Tjernström (1991), and Tjernström and Smedman (1993) observe the complex nature of various coastal boundary-layer flows, especially those associated with the sea breeze and the coastal jet. It is established that the MABL in late spring and early summer can have a depth $H$ of the order of $100 \mathrm{~m}$ or less; that the sea breeze sometimes behaves 'erratically', e.g. it may 'float' at the coastline for a few hours before it quickly penetrates inland, it may be superseded by a coastal jet, and vice versa. This hints at the dynamic features to be considered here.

Many of the observed subtle coastal flow features cannot be explained by known theories. For instance, changes of the sea-breeze propagation speed and structure denote deficiencies of known linear (Dalu and Pielke, 1989) and nonlinear (Feliks, 1988) theories for the sea breeze. Growing evidence about complexity of the coastal ABL suggests a necessity for numerical modeling on meso- $\gamma$ scale for the Baltic coast. This way, diverse effects can be isolated and studied more systematically via parameter sensitivity tests. Emphasis is put on the understanding of how various conditions generate assorted structures in the MABL, not on obtaining exact duplicates of measurements; this is also supported by the common 
restriction for the level of agreement between the measurements and modeling. The former deals with limitations in spatial and temporal representativity (i.e. sampling criteria) of the data collected in an inhomogeneous, time-evolving medium such as the coastal MABL, etc.; the latter considers intrinsic assumptions of the model used, subgrid scale parameterizations, validity of boundary and initial conditions, etc. This work continues the long-term international effort of our Department in studying the coastal mesoscale dynamics using observations, numerical modeling and analytical methods (e.g. Barthelmie et al., 1996; Berger and Grisogono, 1998; Smedman et al., 1997).

\subsection{BACKGROUND}

The numerical 3D simulations addressed here follow late-spring observations presented in Tjernström (1991), his Case III. His case study consisting of a welldocumented sea breeze in the southeast of Sweden (Figure 1) is simulated in Tjernström and Grisogono (1996). A surface parameter sensitivity test is performed in Grisogono and Tjernström (1996). A sensitivity test of a generic type is conducted here. The effect of the principal large-scale wind directions on the thermally forced mesoscale circulations is explored. A few abbreviations used here and in the mentioned studies are: (already defined) the MABL and the local standard time (LST).

The main findings from Tjernström and Grisogono (1996) and Grisogono and Tjernström (1996) are the following. The control simulation conforms to the observations in general while details may vary. The sea-breeze stage is preceded by the coastal jet stage. Development of the coastal jet during the early morning is related to blocking of the stably stratified, shallow MABL by the coastal terrain. The sea breeze occurs on the top of the shallow MABL, $H \leq 100 \mathrm{~m}$, it sojourns and develops at the coastline for several hours and then swiftly penetrates inland. This sea breeze is dependent on the sea breeze at the Kalmar coast and on the terrain-induced flows. The MABL is below a thick near-neutral layer. Even though the coastal terrain is very moderate with elevations $h_{0} \leq 206 \mathrm{~m}$, it largely intensifies spatio-temporal variability of the airflow. There is only insignificant feedback between the nighttime temperature perturbation and the daytime thermally forced circulation, and vice versa. Land surface temperature perturbations govern the configuration more but the sea-breeze front propagation less; they magnify alongshoreline and across-shoreline variability of the ABL. Spatial perturbations of the sea-surface temperature have minor to moderate effects on the circulations considered. Theories for the sea breeze of Rotunno (1983) and Dalu and Pielke (1989) are found inapplicable in this real environment with synoptic wind shear because the theories do not account for background shear and vertically varying stratification. Furthermore, the wind shear itself could have been, in principle, the cause of absence of a counterbalancing return flow which, in turn, adjusts the aspect ratio $\delta$ 


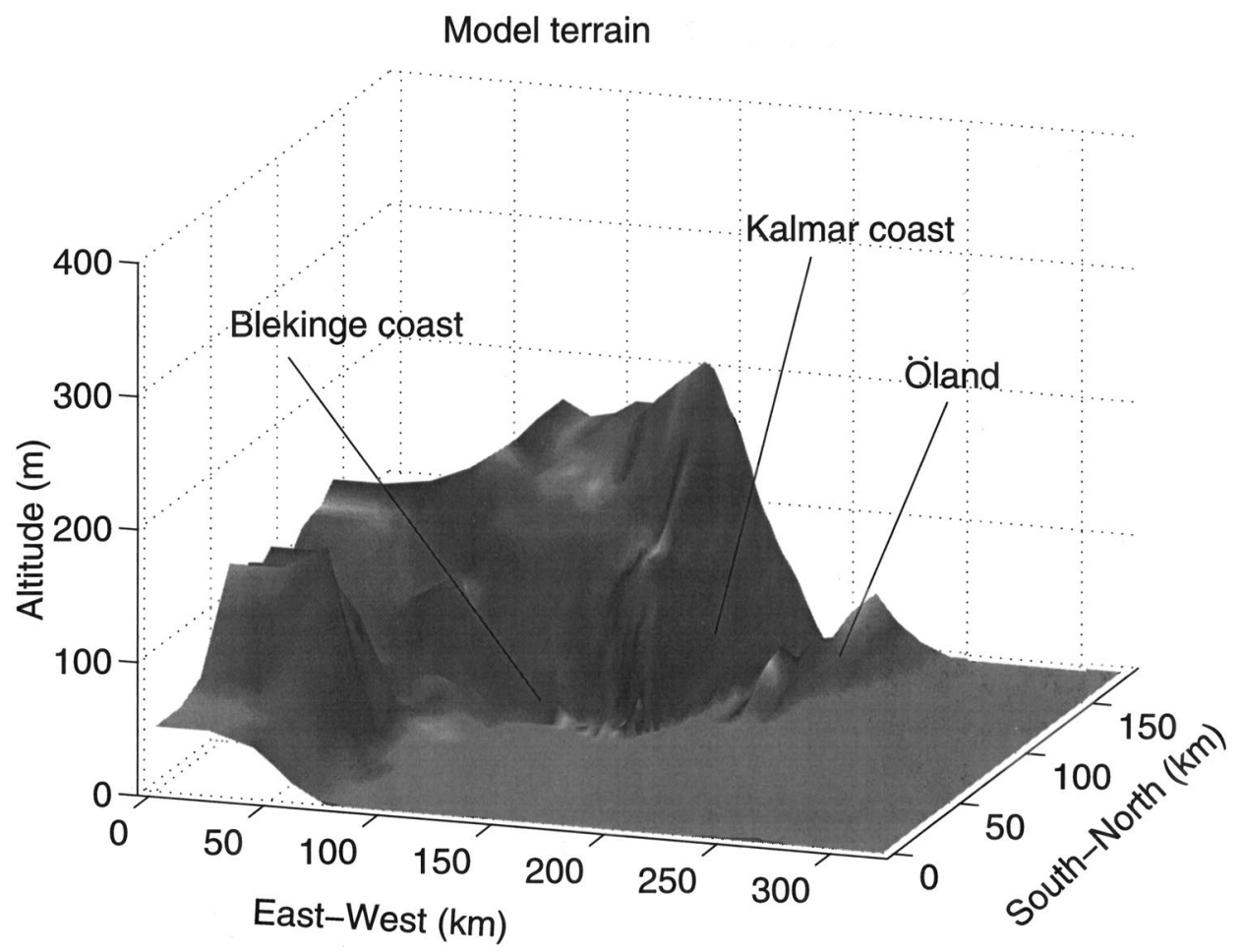

Figure 1. The modeled terrain area in southeast Sweden (southwest of the Baltic sea). The three particular regions have their names written: Blekinge coast (facing south), Kalmar coast (facing east) and the island of Öland (east of the Kalmar coast).

too far from the linear estimation. The nighttime offshore flow consists of drainage flow with an insignificant contribution due to the land breeze.

Systematic effects of large-scale flow characteristics on the sea breeze and related coastal dynamics are still not well-known. Numerical results such as those of Arritt (1993) and Zhong and Takle (1993) give the range of values for important quantities, e.g. the strength of the background wind inhibiting development of the breeze; however, validity of these ranges for assorted real situations needs to be revised. The goal here is to identify and describe small-scale variability of the 3D coastal ABL with respect to the main synoptic wind direction. Hence, the control simulation supporting the observations (Tjernström and Grisogono, 1996) is perturbed here in a unified way so that constant initial wind profile is assigned to each of the four main wind directions. Since other parameters are kept unchanged, wind direction is the only parameter varying among the four simulations presented here. A most intriguing low-level coastal jet with drainage flows, an unusual sea breeze, and an eddy structure are discussed. The coastal eddy structure is analyzed more quantitatively. 


\section{Modeling Procedure}

\subsection{THE MODEL}

A mesoscale, 3D numerical model is employed (the MIUU* mesoscale model). The model solves five governing prognostic and a number of diagnostic differential equations. Horizontal wind components, potential temperature, specific humidity and turbulent kinetic energy (TKE) are calculated prognostically (Enger, 1986, 1990; Tjernström, 1987). Having adopted the hydrostatic and incompressibility approximations, vertical velocity and pressure are obtained diagnostically. These assumptions are reasonable for the sea-breeze modeling (e.g. Pielke, 1984; Arritt, 1989; Yang, 1991). The model uses a higher-order turbulence closure scheme, 'level 2.5', where the turbulent length-scale and anisotropic turbulence stresses are calculated algebraically. Andrén (1990) formulated this parameterization as a fully realizable and wall-corrected scheme for turbulence. The merits of the 'level 2.5' closure in studies of the sea breeze, terrain-induced vortices, etc. are stressed by Arritt and Physick (1989). For the sake of simplicity, parameterizations for clouds and radiative processes are excluded here.

The numerics employed consist of first- and second-order schemes for the model's finite difference equations (Tjernström et al., 1988; Grisogono, 1995; Holmgren, 1995). The equations are solved in a terrain-influenced coordinate system with telescopic distributions of horizontal and vertical gridpoints that allow fine resolution in the area of interest. Boundary conditions are: zero-inflow and gradient outflow for lateral boundaries, no-slip lower boundary condition and constant pressure at the model top. Having the model top sufficiently far above the area concerned means there is no need for using a sponge layer aloft. Pielke describes the dynamic initialization procedure which is employed in the model; here a 1D model is run during most of the afternoon of the preceding day, and then the results are distributed over the modeled area in order to begin the full 3D simulation (also see Enger, 1990).

Various validations, applications and detailed descriptions of the model are found in the literature (e.g. Enger and Tjernström, 1991; Enger et al., 1993; Svensson, 1996a, 1996b). Hence, these are not repeated here. Nonlinearity, timedependence, 3D-capability, the turbulence closure scheme, and sufficient spatiotemporal resolution are the essence of the modeling procedure used. The most recent model review is in Enger and Grisogono (1998) addressing sea-surface temperature effects on coastal mountain gravity-wave breaking.

\subsection{Model SETUP AND INPUT}

The modeled area shown in Figure 1 covers $320 \times 180 \times 3.5 \mathrm{~km}^{3}$ with (westeast $) \times($ south-north $) \times($ vertical $)$ axes, respectively. It is resolved on a $41 \times 23 \times$

\footnotetext{
* Meteorologiska Institutionen Uppsala Universitet (MIUU).
} 
22 grid with the finest resolution in the model center, $(2 \mathrm{~km}) \times(3 \mathrm{~km}) \times(2 \mathrm{~m})$, respectively. The timestep is $15 \mathrm{~s}$. Total $3 \mathrm{D}$ simulation time is $25 \mathrm{~h}$, and results will be discussed for the last seventeen hours. The constant Coriolis parameter is $f=$ $1.21 \times 10^{-4} \mathrm{~s}^{-1}$.

An average value for the background wind speed from Tjernström and Grisogono (1996) is assigned as the constant geostrophic wind speed, $U_{0}=8 \mathrm{~m} \mathrm{~s}^{-1}$. This synoptic wind blows from north, south, east or west, thus forming the four independent simulations. Above the initially neutral $100 \mathrm{~m}$ deep layer, there is almost constant, stable stratification with $\partial \Theta / \partial z \approx 4 \mathrm{Kkm}^{-1}$ (the mean buoyancy frequency is $N_{0}=0.012 \mathrm{~s}^{-1}$ ). Specific humidity decreases monotonically with height from $4.4 \times 10^{-3}$ at the surface, to $3 \times 10^{-3}$ at the model top. The seasurface temperature is kept constant, $12^{\circ} \mathrm{C}$. The land surface temperature follows a sine function with $24 \mathrm{~h}$ period; the amplitude and average temperature is $8{ }^{\circ} \mathrm{C}$ and $12.5^{\circ} \mathrm{C}$, respectively. Based on the parameter $U_{0}^{2} /|R \cdot \Delta T|$ which is much less than unity for most of the time, one assures that the dynamics are mainly driven thermally (e.g. Pielke, 1984); here $R$ is the universal gas constant for air and $\Delta T$ is land-sea temperature difference which is a given function of time. The simulations presented here are idealized ones; most of parameters are kept under control and as simple as possible on purpose - to a large extent like in a laboratory. Hence, a surface energy balance is deliberately not utilized here. Moreover, McCumber and Pielke (1981) show that the prediction of the surface temperature is very responsive to soil moisture values, and these values are unknown here. Also, one of the authors (Tjernström, 1988) shows with this model that an appropriately assigned surface temperature forcing performs close to that obtained by the surface energy balance anyway. Finally, Tjernström and Grisogono (1996) use the same surface temperature forcing and obtain an acceptable agreement between observations and the case study modeling which differs from the results presented here only in the background wind. Therefore, we are convinced that for the purpose of this study, the model briefly described, its setup and input are reasonable.

\section{Simulation Results}

There are distinctions between the nighttime and daytime coastal mesoscale circulations; therefore, the analysis is similarly pursued. Only the most interesting features identified with small-scale variabilities from the each simulation run are presented; details of an eddy pattern are offered. Table I outlines the appearance of primary mesoscale formations versus the four simulations.

\subsection{NightTime Flows: COASTAL JET AND DRAinAGE}

Figure 2 shows horizontal wind fields $24 \mathrm{~m}$ above the surface at 2:00 LST for easterly (2a) and southerly (2b) geostrophic wind. Both cases consist of inflows coming 


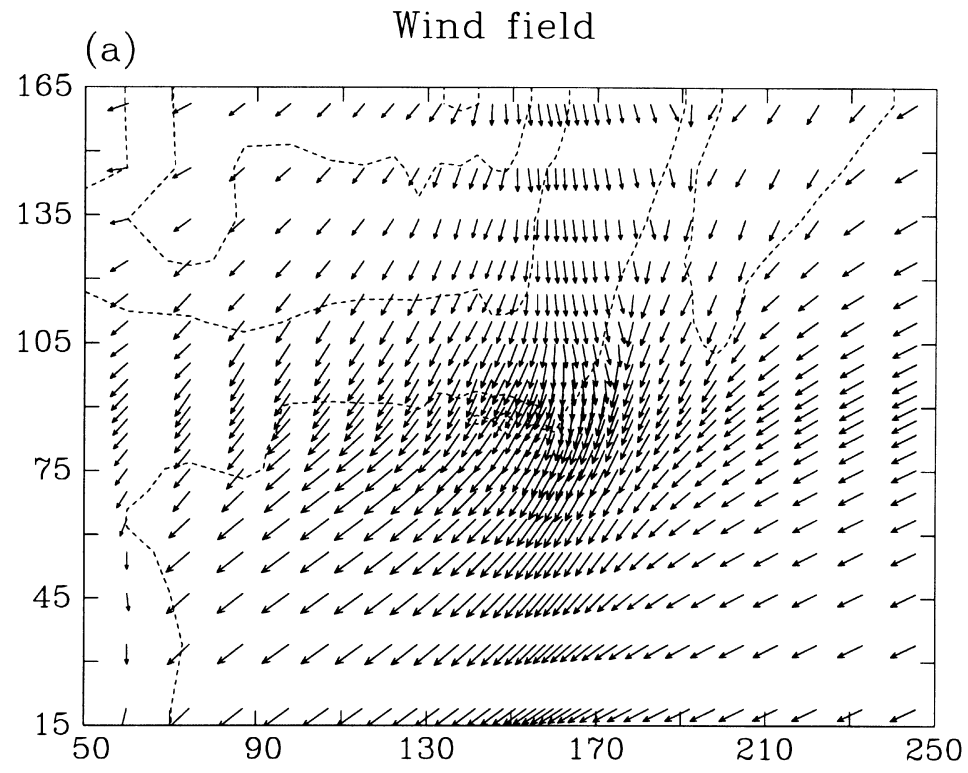

$5 \overrightarrow{\mathrm{m} \mathrm{s}} \mathrm{s}^{-1}$

(b)

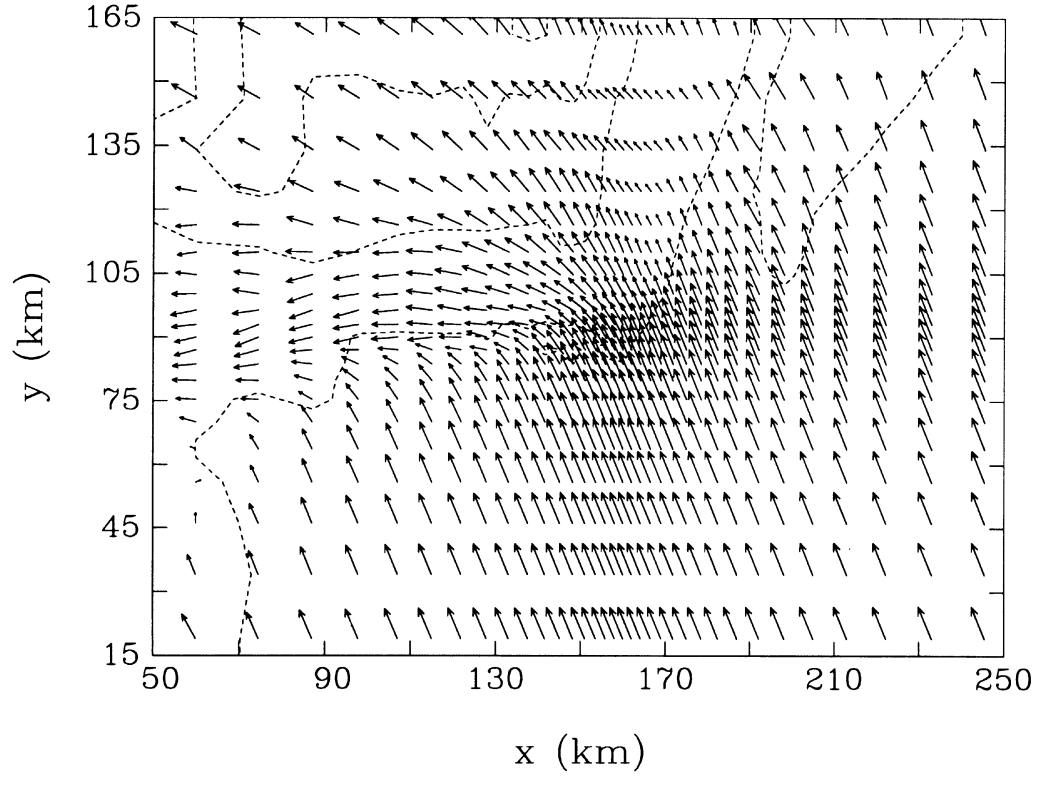

$5 \overrightarrow{\mathrm{m}} \mathrm{s}^{-1}$

Figure 2. Horizontal wind field $24 \mathrm{~m}$ above the surface at 0200 LST for: (a) easterly and (b) southerly constant geostrophic wind (always set to $8 \mathrm{~m} \mathrm{~s}^{-1}$ ). Convergence zones develop near the coastlines that are roughly perpendicular to the background wind vector. The maxima here are: (a) $7 \mathrm{~m} \mathrm{~s}^{-1}$ just south of the Blekinge coast, (b) a little over $6 \mathrm{~m} \mathrm{~s}^{-1}$ in the southeast segment of the figure. 
TABLE I

The basic mesoscale features discussed in this study: coastal jet, drainage flow, sea breeze and eddy, versus the four principal wind directions

\begin{tabular}{lllll}
\hline Wind direction & Coastal jet & Drainage & Sea breeze & Eddy \\
\hline North & Yes & Yes & Yes & Yes \\
South & Yes & Yes & Yes & No \\
East & Yes & Yes & Yes & No \\
West & Yes & Yes & Yes & No \\
\hline
\end{tabular}

exclusively (easterly) or primarily (southerly) from over the sea. These fields differ from each other due to the terrain and coastline inhomogeneity imposing an irregular amount of friction and blocking for the incoming airflow. An expected overall turning of the undisturbed incoming airflow, approaching an increase in surface friction, to the left from the geostrophic wind direction is observed. Here the MABL approaching the land starts to be affected by the terrain roughly $70 \mathrm{~km}$ (easterly) and $60 \mathrm{~km}$ (southerly) offshore. This is somewhat more than the corresponding Rossby radii of deformation $\left(R=N_{0} H_{0} / f, H_{0}\right.$ is the vertical scale of the perturbation). Besides far-offshore wind maxima in both cases, the easterly case also exhibits a secondary maximum located out over the sea south of the Blekinge coast. The terrain, primarily perpendicular to the geostrophic wind (i.e., the Kalmar coast and Öland perpendicular to the easterly, and the Blekinge coast to the southerly wind), generates a low-level wind component that effectively opposes the geostrophic flow. While Figure 2a manifests a relatively larger area exhibiting drainage flow, Figure $2 b$ indicates a localized drainage-type flow mainly at the Blekinge coast. Both cases display the existence of the coastal jets which apparently interact with the coastal drainage wind beneath (not shown).

Vertical cross-sections over the Kalmar coast and the island of Öland for the easterly case are presented in Figure 3; this corresponds to the situation in Figure 2a for $y=116 \mathrm{~km}$. The overall maximum terrain slope is $0.24^{\circ}$ and in this figure it is $0.22^{\circ}$. Figures $3 \mathrm{a}$ and $3 \mathrm{~b}$ display the $u$ - and $v$-components, respectively. Since the Kalmar coast extends directionally $20^{\circ}-200^{\circ}$, these components essentially correspond to the across-shore and along-shore wind components, respectively. The drainage wind develops despite the opposing geostrophic flow (Figure 3a). It is confined below the very low coastal jet (Figure $3 \mathrm{~b}$ ). The minimum gradient Richardson number, $\min (\mathrm{Ri})$, in the layer between is slightly less than unity implying that there can be intermittent turbulent interaction. The coastal jet is roughly perpendicular to the geostrophic wind and reaches the same magnitude $\left(7 \mathrm{~m} \mathrm{~s}^{-1}\right.$ in Figure $3 \mathrm{~b}$, and $8 \mathrm{~m} \mathrm{~s}^{-1}$ further south where it turns more inland). Total wind speed near the coast experiences a maximum low-level vertical shear of about 

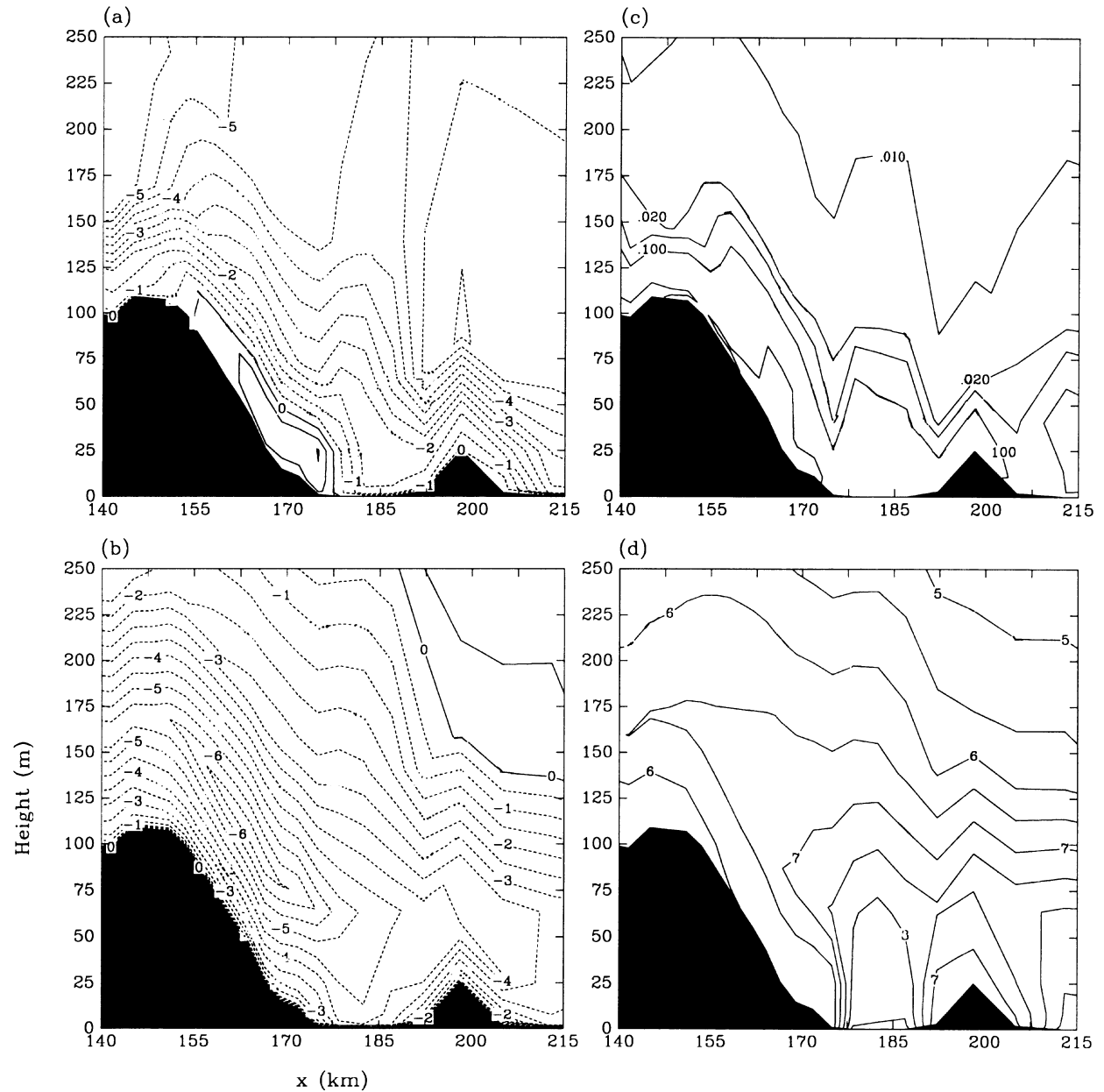

Figure 3. Vertical cross-sections $(x, z)$ for the easterly case at $y=116 \mathrm{~km}$ ( $y$ is toward north, also see Figures 1 and 2) and 0200 LST for four variables: (3a) the $u$-component conforming to the across-shore wind component (always in $\mathrm{ms}^{-1}$ ), (3b) the $v$-component conforming to the along-shore wind component, (3c) TKE (isolines: 0.01, 0.02, 0.05, 0.1, $0.2 \mathrm{~m}^{2} \mathrm{~s}^{-2}$ ) and (3d) specific humidity (in $\mathrm{gkg}^{-1}$ ).

$7 \mathrm{~m} \mathrm{~s}^{-1} /(60 \mathrm{~m})$ and $20 \%$ more $25 \mathrm{~km}$ inland. While Grisogono and Tjernström (1996) show that a low-level mesoscale thermal wind is responsible for the coastal jet under weak low-level background winds, this statement does not hold here. Although the TKE field (Figure 3c) over the land maintains its average vertical extent from over the sea, it shows significant variations, like the other variables, over the strait between the Kalmar coast and Öland. It is difficult to find the top of the stable ABL. Here it is estimated based on corresponding mean values for the top from all fields $\left(u, v\right.$, TKE, $\Theta_{v}$ and humidity). This average MABL is about $190 \mathrm{~m}$ thick ( $\pm 50 \mathrm{~m}$ or more), rises in the coastal area and develops in an ABL 
about $300 \mathrm{~m}$ thick; this means a total ABL slope (with terrain added) of roughly $200 \mathrm{~m} /(40 \mathrm{~km})\left(=0.3^{\circ}\right)$. The TKE field itself does not support the finding about the ABL slope being larger than the local terrain, but this comes out when all important factors are taken into account together (inversions, wind turning, etc.). It is likely that short evanescent gravity waves are induced at the strait, and could, within the linear wave theory, promote an increase of the top of the MABL while leaving the flow energetics largely undisturbed (Gill, 1982). Nevertheless, the bulk of the rising MABL is due to vertical motions caused by the convergence and friction over the strait area. Specific humidity (Figure 3d) loosely agrees with the idea about the interaction between the coastal jet and the drainage wind because there is an increased mixing of specific humidity (in this model setup, acting nearly as a passive tracer) above the Kalmar coast (see $6.5 \mathrm{gkg}^{-1}$ isoline).

Vertical cross-sections over the Blekinge coast for the southerly case are presented in Figure 4; this corresponds to the situation in Figure 2b for $x=122 \mathrm{~km}$. The southerly wind inhibits drainage at the Kalmar coast, but supports a katabatic wind at the west coast of Öland; meanwhile, the Blekinge coast manifests a drainage flow despite the opposing geostrophic wind and very moderate slope of the local terrain. Figure 4a shows a coastal jet situated only $20-30 \mathrm{~m}$ above ground; its maximum speed slightly exceeds $4 \mathrm{~m} \mathrm{~s}^{-1}$. The drainage together with the opposing ambient wind is shown in Figure $4 \mathrm{~b}$. Spatial onset of the drainage wind is established below the inland advent of the coastal jet (compare Figure 4a and $4 \mathrm{~b}$ ); the layer between the surface and the coastal jet is identified with min(Ri) $\leq 0.3( \pm 0.1)$. This signifies an interaction and mixing between the two stratified flows (Manins and Sawford, 1979). Corresponding fields are displayed: specific humidity (Figure 4c) and virtual potential temperature $\Theta_{v}(4 d)$. Specific humidity is reasonably mixed within the area occupying the drainage and coastal jet flow. Both Figures $4 \mathrm{c}$ and $4 \mathrm{~d}$ imply that an abrupt change of the MABL depth is preferred when the flow approaches the coastline, rather than a gradual, terrain-following adjustment.

As time proceeds in the southerly case and the surface warms up, the drainage disappears, the coastal jet elevates and overall wind speed increases. A loosely defined and short-lived sea breeze (between 0600-0800 LST) is surpassed by the ambient south-southeasterly wind while the coastal jet moves over the coastline (0800 LST), sinks and dissolves in the MABL's wind field (1000 LST).

\subsection{DAYTIME FLOWS: SEA BREEZE}

The emphasis of this subsection is on an irregular sea breeze. An irregular sea breeze develops in the ambient wind field with a weak onshore component $(V \leq$ $\left.1 \mathrm{~m} \mathrm{~s}^{-1}\right)$ and a super-geostrophic along-shore component $\left(U \approx 11 \mathrm{~m} \mathrm{~s}^{-1}\right.$ for $300 \mathrm{~m}$ $<z<1200 \mathrm{~m}$ ) before $0900 \mathrm{LST}$; the geostrophic wind is westerly $8 \mathrm{~m} \mathrm{~s}^{-1}$. This is the only case where the oncoming flow comes exclusively from over the land. The next three figures address the crossectional evolution of the sea breeze in terms 

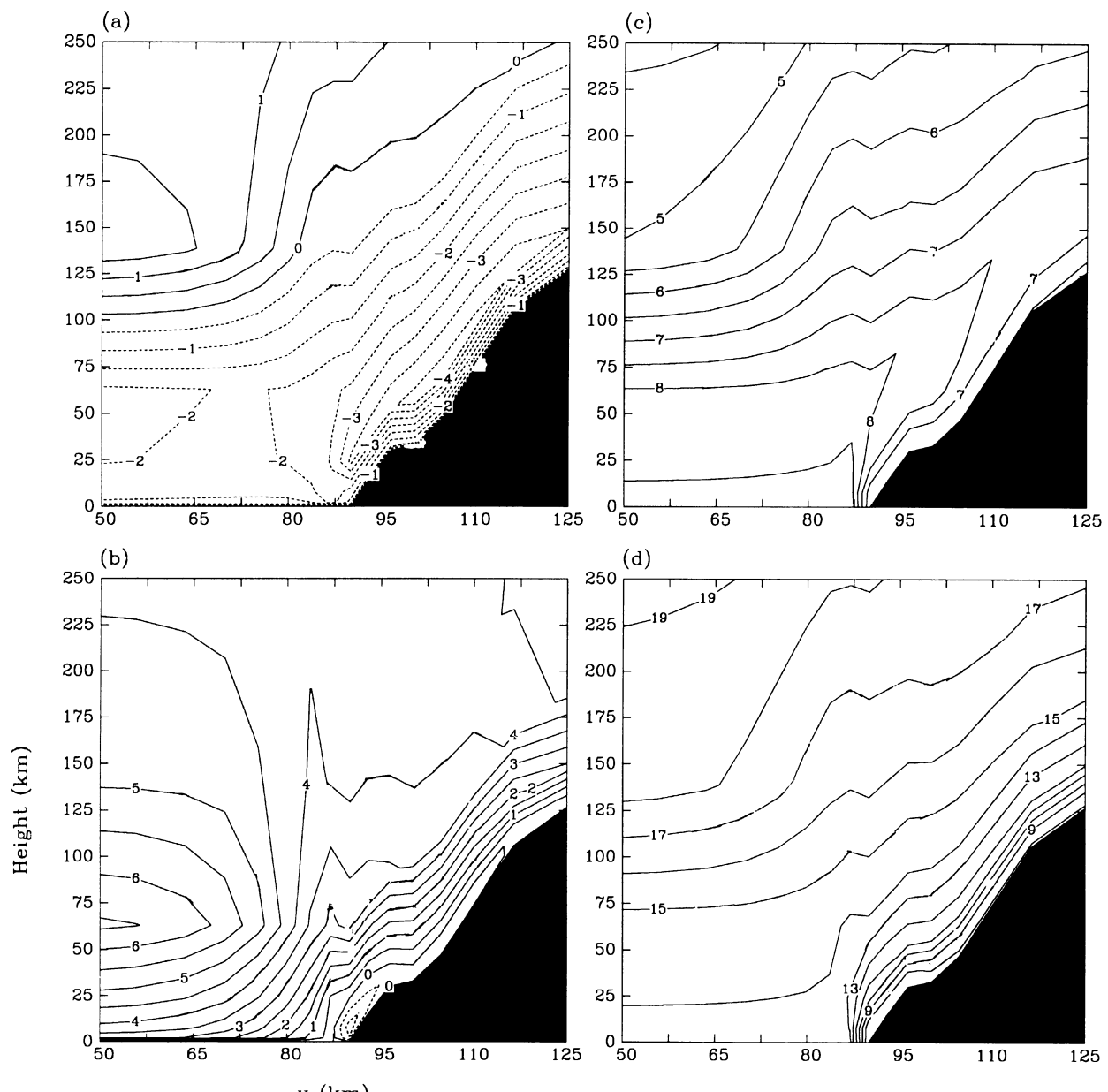

Figure 4. Vertical cross-sections $(y, z)$ for the southerly case at $x=122 \mathrm{~km}$ ( $x$ is toward east) and 0200 LST for four variables: (4a) the $u$-component corresponding to the along-shore wind component, (4b) the $v$-component corresponding to the across-shore wind component, $(4 \mathrm{c})$ specific humidity and $(4 \mathrm{~d})$ virtual potential temperature $\Theta_{v}\left(\right.$ in $\left.{ }^{\circ} \mathrm{C}\right)$.

of the along-shore and across-shore wind fields ( $u$ and $v$, respectively), $\Theta_{v}$ (or spec. humidity) and TKE; sub-figures a, b, c and d, respectively. The cross-sections are taken at the Blekinge coast $(x=138 \mathrm{~km})$ with respect to three subsequent times. During the morning, the sea breeze gains in size, maximum onshore speed and vertical velocity $\left(w_{\text {MAX }} \leq 0.2 \mathrm{~m} \mathrm{~s}^{-1}\right)$. The end of this stage is displayed in Figure 5 at 1100 LST. Note that the $u$-field (Figure 5a) providing most of the total wind exhibits multiple-scale variations: (1) considerable vertical shear $\partial u / \partial z>0$ throughout the cross-section, (2) systematic onshore decrease in the lowest km, i.e. $\partial u / \partial y<0$, and (3) striking fluctuations superimposed on the sloping, nonparallel, $u=$ constant surfaces. Figure $5 \mathrm{~b}$ showing the $v$-field displays the sea- 

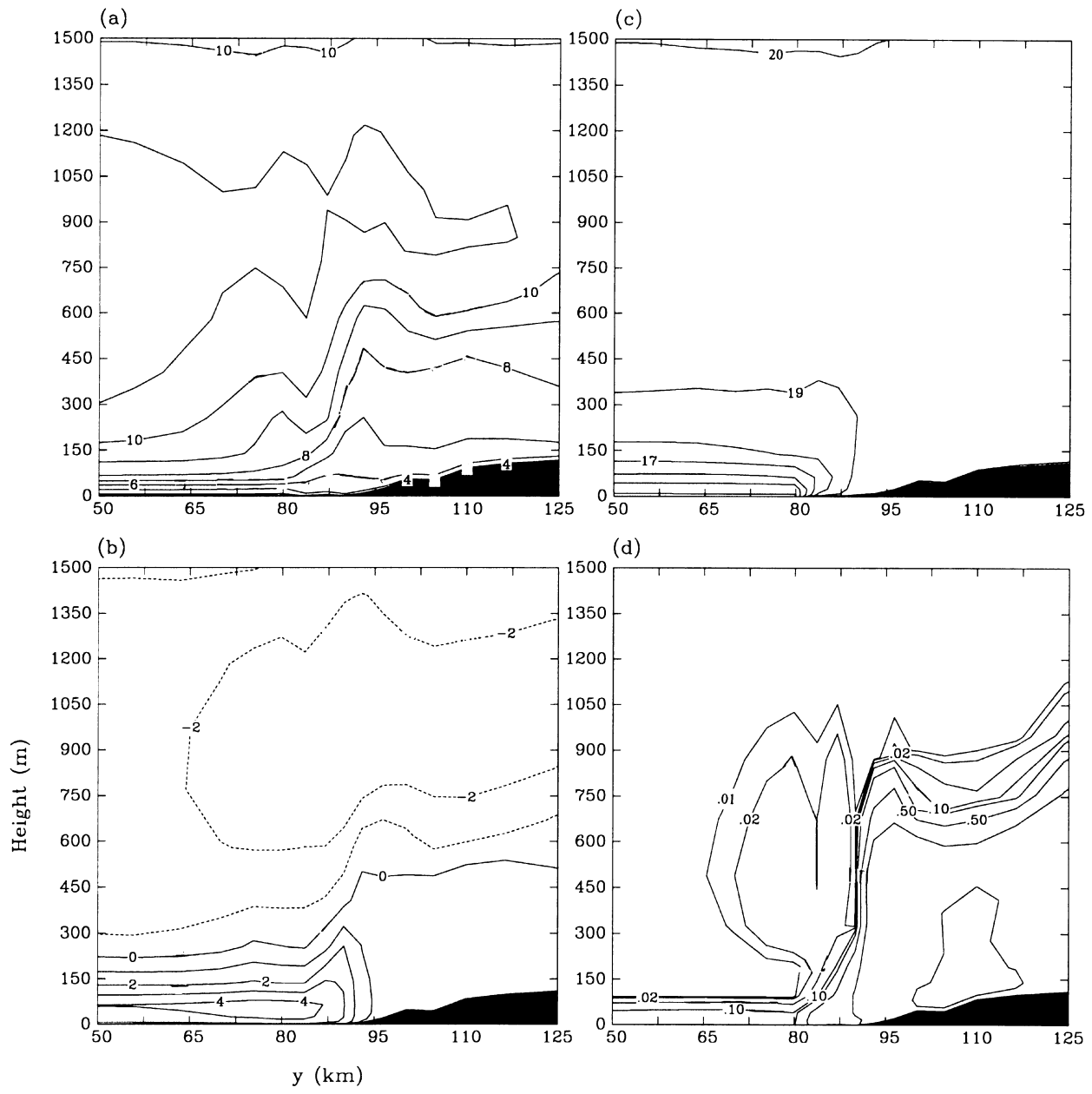

Figure 5. Vertical cross-sections $(y, z)$ for the westerly case at $x=138 \mathrm{~km}$ at 1100 LST showing: (5a) the along-shore wind component $u$ (aligned with the geostrophic wind), (5b) the across-shore wind component $v,(5 \mathrm{c}) \Theta_{v}$-field and (5d) TKE (the largest two values for isolines are 1 and $1.5 \mathrm{~m}^{2} \mathrm{~s}^{-2}$ ).

breeze front head $10 \mathrm{~km}$ inland and roughly two times higher than the sea-breeze current behind. The maximum onshore velocity is around $4.5 \mathrm{~m} \mathrm{~s}^{-1}$. The zones with the largest vertical shears are in the MABL $\left(\approx 3 \mathrm{~m} \mathrm{~s}^{-1} /(100 \mathrm{~m})\right)$ and in the middle of the inland convective $\mathrm{ABL}\left(\approx 2 \mathrm{~m} \mathrm{~s}^{-1} /(100 \mathrm{~m})\right)$. Hence, a compensatory type of flow gradually but non-monotonically slopes over land (from the sheared, convective $\mathrm{ABL}$ ) down toward the MABL top. The ambient and the sea-breeze stratifications are presented by $\Theta_{v}$ in Figure 5c. The structure of the coastal ABL is also illustrated by its TKE in Figure 5d. The strongest gradients of the TKE roughly match the strongest shear zones. Furthermore, the MABL is confined in the lowest $100 \mathrm{~m}$, the TKE related to the sea-breeze frontal zone is very heterogeneous and shows a complicated pattern. There are ripples on an elevated, asymmetric 
turbulent 'blob' related to the upper part of the sea-breeze front (Figure 5d). While the rapid change of stratification at the coastline dictates a distinct onshore edge of the 'blob', the offshore edge is more relaxed hanging above the MABL as a fraction of the elevated TKE is advected out over the sea. The upper and offshore 'blob' sections are associated with weak stability and strong shear, thus being susceptible to shear-driven instabilities.

The 3D frontogenetic function, $\mathrm{d}|\nabla \Theta| / \mathrm{d} t$, contains twelve terms (e.g. Bluestein 1986) even without turbulent fluxes. Though very interesting, a quantitative analysis of the sea-breeze frontogenetic function is beyond the scope of this study. A qualitative analysis of the frontogenetic terms for the Blekinge coast shows that not all horizontal-deformation terms are positive, as one may have expected based on other studies (e.g. a 2D study by Arritt, 1993). This means that the total effect from the horizontal-deformation terms might not be very strong in generating the sea breeze at the Blekinge coast which gives a chance to other effects to govern the frontogenetic balance (e.g. tilting, and horizontal gradients of the vertical turbulent flux divergence) as well as their 3D time-dependent interactions.

The coastal flow is altered during the next hour. The cross-sections at 1200 LST are shown in Figure 6. The variations of the (1) and (3) type introduced in this subsection are appreciably smoothed while the (2) type intensifies. This intensification follows a sharpening and narrowing of the sea-breeze front. The sea-breeze front is forced backward to the shoreline, and $\partial u / \partial z$ decreases over the land thus moderately reducing the shear in the convective ABL. There is more elevated offshore than low-level onshore momentum transport which restrains the sea breeze. This kind of over-compensatory flow with respect to the local flow, i.e., locally unbalanced sea breeze at the Blekinge coast, is due to the $3 \mathrm{D}$ effects and the flow evolution around the Kalmar coast. Such 3D regional coupling of local flows is also found in Tjernström and Grisogono (1996). On the other side, Banta et al. (1993) observed a sea breeze in the Monterey Bay that behaved differently: they found no compensatory flow and an energetic inland sea-breeze penetration. Reduction of the sea-breeze horizontal scales generally promotes frontogenesis due to convergence while the coastline is related to the frontogenesis due to differential diabatic heating. Horizontal variations in $\Theta_{v}$ appear in the upper part of the MABL and at the coast. The TKE field shown in Figure $6 \mathrm{~d}$ displays the most intense ABL at this cross-section throughout the period of simulations. Here the TKE extends higher up and out above the sea, like a plume, over the collapsing MABL several tens of km offshore (compare to Figure 5d). Drag due to turbulence and sheardriven waves on the MABL from aloft obstructs a vigorous development and inland penetration of the sea breeze (roughly on the meso- $\gamma$ scale and shorter). This works together with the mentioned sea breeze stalling at the Blekinge coast because of the flow at the Kalmar coast and an excess of the Kalmar coast's sea-breeze compensatory flow (roughly on the meso- $\beta$ scale). The most energetic turbulent zone, initially situated more inland, moves toward the coastline, elongates vertically and narrows horizontally. Strong turbulent friction at the coastline is associated with 

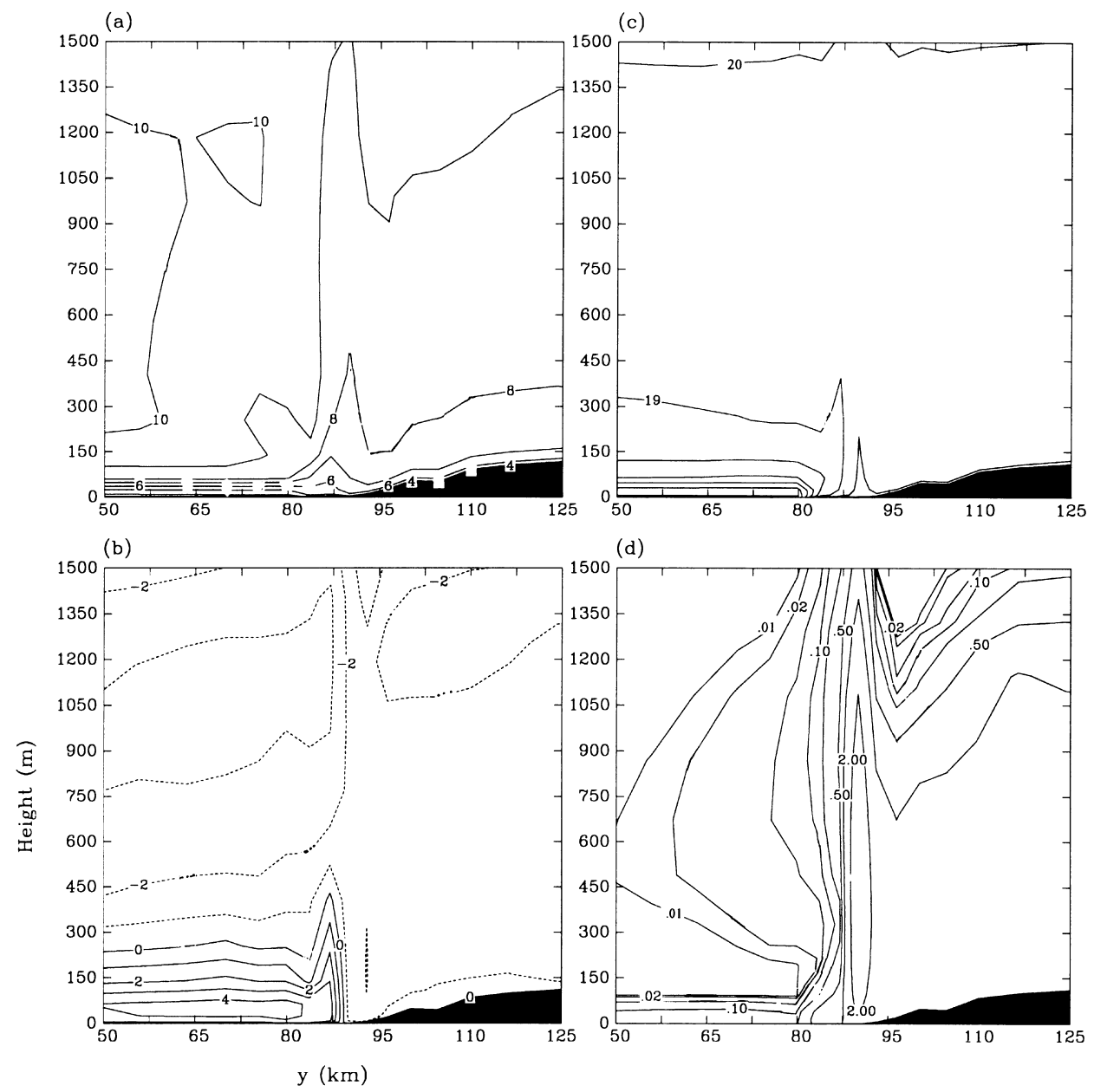

Figure 6. Same as Figure 5 but at 1200 LST. The sea breeze has moved backward and evolves at the coastline. The largest two values for the TKE isolines in Figure $5 \mathrm{~d}$ are 1 and $2 \mathrm{~m}^{2} \mathrm{~s}^{-2}$.

the high TKE values $\left(>2 \mathrm{~m}^{2} \mathrm{~s}^{-2}\right)$ in the sheared convective ABL. It obstructs the sea-breeze inland penetration, i.e., it performs a partial blocking to the sea breeze together with other retarding effects such as the low-level flow turning to the northeast following the main coastline. Having hypothetical measurements of this sea breeze between 1100 and 1200 LST in the same class (because these are taken only over one hour) would yield a false observational conclusion about the sea-breeze evolution. In other words, if the data between 1100 and 1200 LST were averaged together, the averaged values will give a false statistical picture of the actual sea-breeze evolution. This is important for interpretation of field data from a complex-terrain area, as in this study where the small spatial scales can induce flow reversals and other flow alterations on comparatively small time scales. 

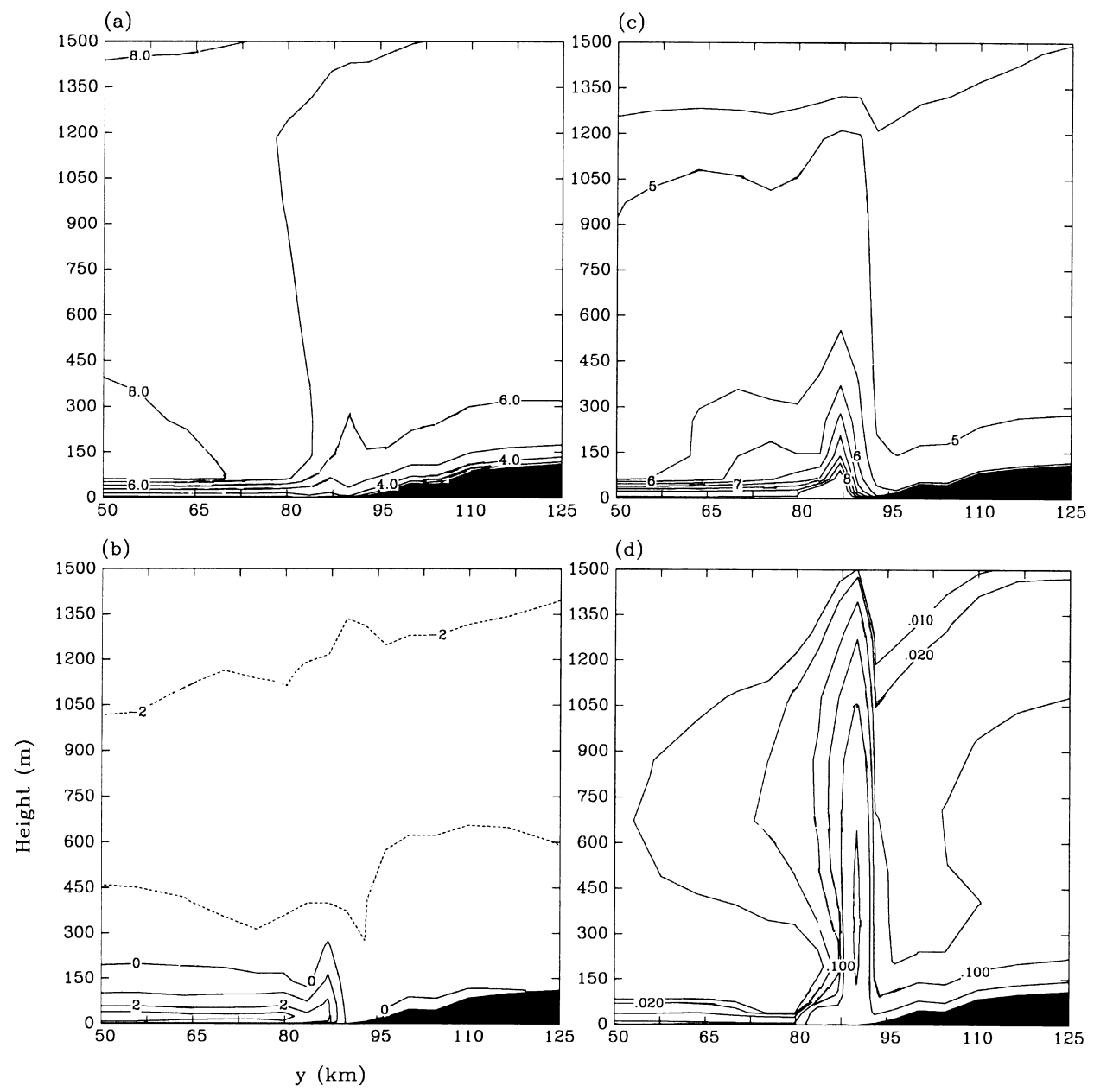

Figure 7. Same as Figure 5 but at 1500 LST and specific humidity is shown in $7 \mathrm{c}$ (instead of virtual potential temperature in Figure $5 \mathrm{c}$ and $6 \mathrm{c}$ ). The sea breeze just before inland penetration. The largest two values for the TKE isolines in Figure $7 \mathrm{~d}$ are 0.5 and $1 \mathrm{~m}^{2} \mathrm{~s}^{-2}$.

Tilting and adjusting of the shear zones in the u-field is largely completed over the next three hours (Figure 7a). The sharp sea-breeze front clearly separates the momentum distribution between that over the sea and over the land. Vertical velocity ranges between -0.2 and $+0.5 \mathrm{~m} \mathrm{~s}^{-1}$ in down- and updraughts, respectively (not shown). Although these values are not large, they show spatial variations that affect the frontogenesis via tilting (mainly the term $-|\nabla \Theta|^{-1} \partial \Theta / \partial y(\partial w / \partial y) \partial \Theta_{v} / \partial z$ ). Sloping shear ( $z$ - and $y$-components) in the $v$-field shown in Figure $7 \mathrm{~b}$ has decreased and now occurs only over the sea and above the coastline. Figures $7 \mathrm{~b}$ and $7 \mathrm{c}$ suggest that the upper part of the MABL is still susceptible to small-scale fluctuations like shear-driven waves and their instabilities; the related $\min (\mathrm{Ri})$ around $25 \mathrm{~m}$ height takes values around $0.9 \pm 0.5$ locally, suggesting possible intermittent 
mixing due to wave-turbulence interactions. Similar wave-like disturbances are seen in measurements (Tjernström, 1991; Finkele et al., 1995) and 2D-benchmark, numerical simulations (Sha and Kawamura, 1991). Due to continuous changes in the flow, transience and smallness of these waves, it is difficult to extract their 'classical' wave properties; nevertheless, the name wave is kept here due to obvious resemblance with ideal waves.

The convergence zone associated with the standing sea breeze at the Blekinge coast occurs between 1130 and 1530 LST. Meanwhile, the flow downwind from the corner where both coasts meet (see Figure 1) is turning toward north-northeast, as dictated by the coastline geometry and a strong convergence zone at the Kalmar coast. Overall wind turning in the MABL toward the northeast, following the coastline turning to north-northeast, is apparent within roughly $100 \mathrm{~km}$ offshore (again roughly the Rossby radius of deformation). This northeasterly flow forms a coastal jet below the MABL inversion during the early afternoon east of the island of Öland. None of the east-facing coasts develop a sea breeze - there is a coastal jet instead. The intensification of the convective ABL supports the increased friction and promotes the mesoscale wind turning following the coastline. The sea breeze at the Blekinge coast, similar to a gravity current and no more than $200 \mathrm{~m}-$ $300 \mathrm{~m}$ thick, penetrates inland around 1530 LST. During this period, it travels with the speed of $2 \mathrm{~m} \mathrm{~s}^{-1}$, then accelerates and dissolves in a favorable, lowlevel mesoscale southwesterly wind (not shown). Prior to this inland sea-breeze penetration, the coastal jet east of the island of Öland weakens. Hence, the sea breeze at the Blekinge coast appears to be locked in phase with the coastal jet at the downwind perpendicular coast. After the coastal jet at the Kalmar coast has weakened sufficiently, the sea breeze at the Blekinge coast may propagate inland. The discussion presented suggests that redistributions of the sheared, convective ABL altering the ambient flow have considerable effects on the evolution of the coastal airflow. Interplays between the coastline geometry, terrain, etc., govern whether a sea breeze shall be suppressed or enhanced, standing at the coast or swiftly penetrating inland, locked up in phase with another dynamic structure, or almost freely self-developing.

Other simulation results that are not shown here suggest that if the coastline west from the Blekinge coast was straight, i.e., without an orthogonal turning roughly between $70 \mathrm{~km}<x<100 \mathrm{~km}$ and $70 \mathrm{~km}<y<90 \mathrm{~km}$, the convergence zone would be about $20 \mathrm{~km}$ inland, weaker and more curved (crossing the Blekinge coast). A smoothing of terrain elevations west and southwest of Blekinge, in addition to the hypothetical coastline stretching, would further modify the inland curvature and weakening of the convergence zone. The zone would be more transient and non-stationary, the sea breeze would not be held at the coastline (while the shear-driven waves would fade away) and there would not be any significant coastal jet east of the island of Öland.

A simpler sea-breeze flow occurs for the easterly case, it penetrates inland around the noon while progressing more firmly on the west side of the Blekinge 
coast. Its sea-breeze front has more than doubled the vertical extent of the one already described in detail, but a smaller offshore extent of only about $30 \mathrm{~km}$ (dictated by an overall low-level deflection as the ambient flow approaches the land). Hence, the aspect ratio $\delta$ is considerably smaller in the easterly than in the westerly case.

\subsection{DAYTIME Flows: MESOSCALE EDdiES}

The most interesting feature in the northerly flow is a low-level eddy-pattern south of the corner-land (where the Kalmar coast and Blekinge coast meet) and the southern tip of the island of Öland during the mid to late afternoon. No regular sea breeze opposing the northerly geostrophic wind occurs in this 3D flow. On the contrary, a 2D simulation for a corresponding $(\mathrm{y}, \mathrm{z})$ cross-section over the Blekinge coast showed a weak $\left(0 \leq v \leq 1 \mathrm{~m} \mathrm{~s}^{-1}\right)$, shallow sea breeze situated offshore in the early afternoon and implying a qualitative agreement with Arritt (1993) who detects a sea-breeze circulation in offshore synoptic flow as strong as $11 \mathrm{~m} \mathrm{~s}^{-1}$. Moreover, the 2D run shows a horizontally spread, low-level jet toward the west and downwind from the weak, offshore located sea breeze. One expects that the 3D flow, having the additional degree of freedom in the horizontal, would undertake another spatio-temporal evolution, different than its 2D coastal surrogate. Only several offshore gridpoints in the 3D run show a low-level wind opposite to the geostrophic flow, and these are associated with the eddy pattern, not with a sea breeze.

A disturbance in the low-level wind field occurs at the strait exit between the mainland and Öland after 0900 LST. It gives rise to a northerly low-level coastal jet initially centered at $200 \mathrm{~m}$ height. This coastal jet is a continuous source of shear and during the afternoon, when the sea-breeze type of perturbation is maximized, it supports a mesoscale eddy structure downwind from the southernmost points of the strait exit. Figure 8 is representative for the afternoon's dynamics; the vector wind, scalar wind and $\Delta \Theta_{v}$-fields at $24 \mathrm{~m}$ and 1530 LST are shown in Figures 8a, $8 \mathrm{~b}$ and $8 \mathrm{c}$, respectively. The first, larger eddy-type of flow is located south of the corner-land while the second, smaller one, appears downwind from the southern tip of Öland (Figure 8a). Note there are two convergence zones with wind speed minima on both sides of the coastal jet exit (Figure 8b). Tongues of relatively cold air imbedded into the strait (nearly coinciding with the coastal jet) indicate the presence of the sea-breeze type of disturbance (Figure 8c). The eddy structure is weaker and inclined downwind at higher levels. It is present up to about $500 \mathrm{~m}$ and reaches the model's south lateral boundary about $85 \mathrm{~km}$ offshore (not shown). Both the coastal jet and eddy pattern begin to fade away after 1730 LST, the former dissolves and advects out of the domain, and the latter weakens, lifts up and moves eastward.

Vertical vorticity is not clearly defined in a non-orthogonal coordinate system; however, it is identical to that in the Cartesian system $(\zeta=\partial v / \partial x-\partial u / \partial y)$ when computed over the sea. Here we only consider the vorticity over the sea. 


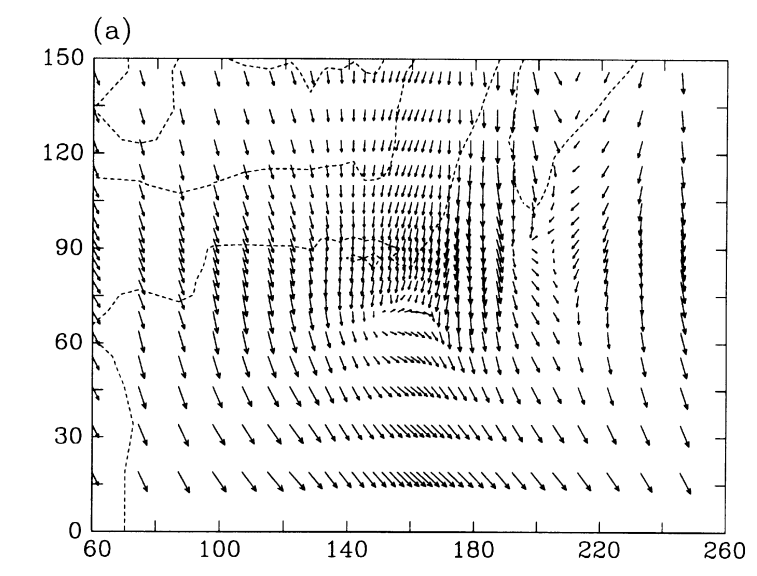

(b)

$5 \overrightarrow{\mathrm{m} \mathrm{s}} \mathrm{s}^{-1}$
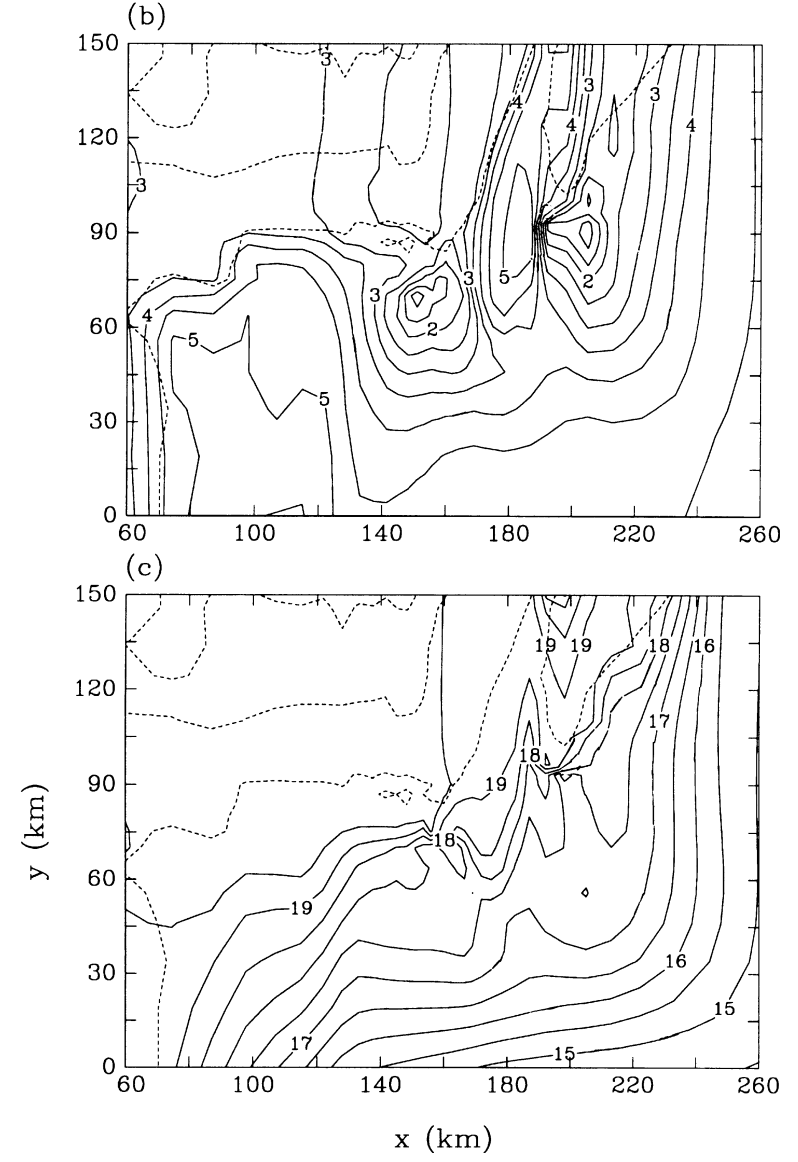

Figure 8. Horizontal cross-sections for the northerly case $24 \mathrm{~m}$ above the surface at 1530 LST: (a) vector wind field, (b) the scalar wind field and (c) the $\Theta_{v}$-field. Two asymmetric mesoscale eddies exist separated by the coastal jet. 

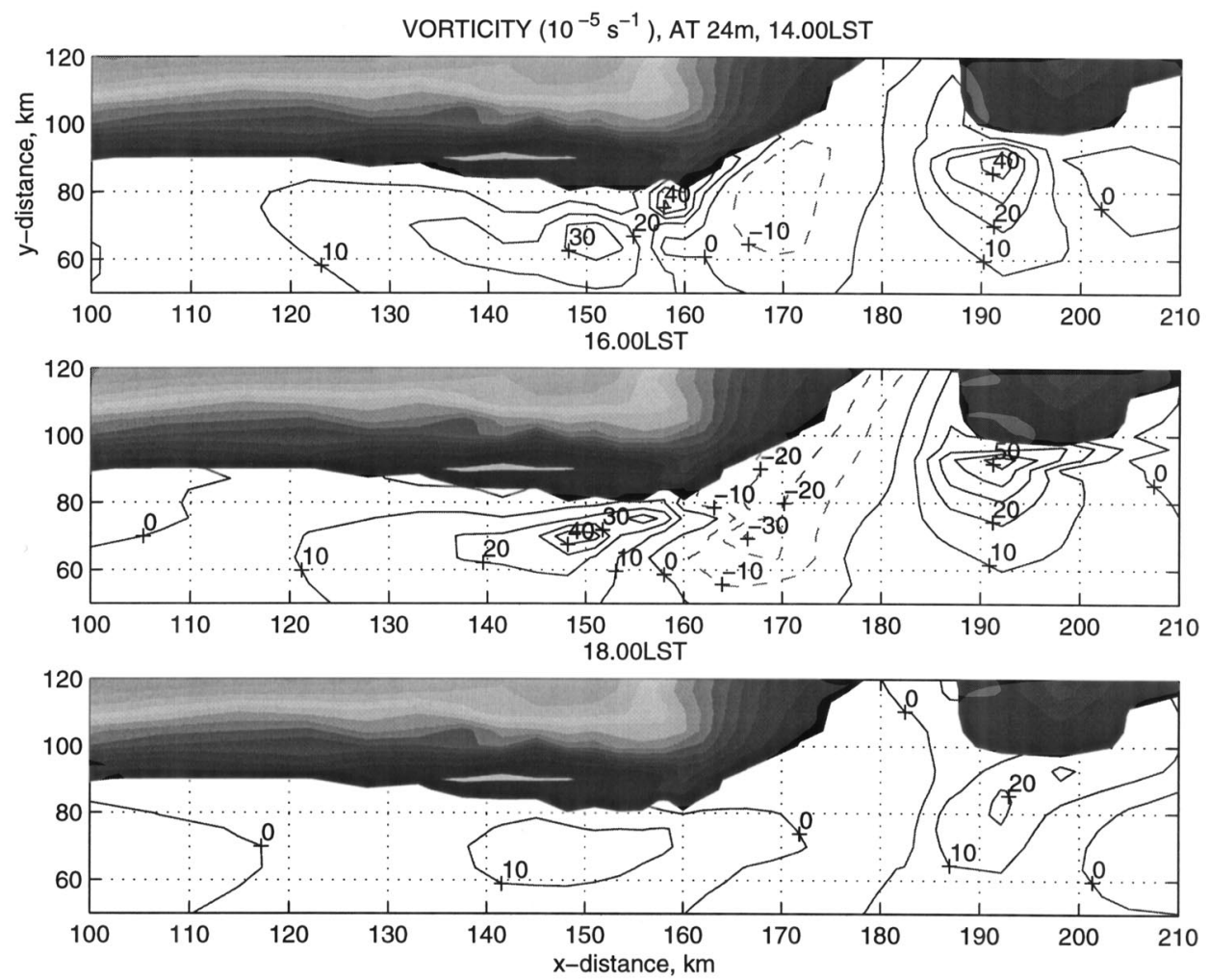

Figure 9. Vorticity field at $24 \mathrm{~m}$ over the sea for the northerly case (the land is shaded). The eddy structure exists over four hours in the mid to late afternoon. Extreme values are reached just after 1600 LST (middle panel - half an hour after Figure 8).

Diagnostic vorticity fields at $24 \mathrm{~m}$ and three subsequent times spanning over four hours are displayed in Figure 9. These four hours, 1400-1800 LST, are roughly the eddies lifetime. After a vigorous and spatially elusive onset, the eddy structure reaches its vorticity extreme value briefly after 1600 LST (Figure 9, middle panel). The decay is more tempered and spatially better defined when compared to the onset. The vorticity tendency equation suitable for mesoscale modeling is straightforward to derive (e.g. Pielke, 1984; Kessler and Douglas, 1991). An expression for vorticity tendency, $\zeta_{t}$, in the MIUU mesoscale model used here is equivalent to that in Kessler and Douglas (their Equation (3)). It is written here for clarity and discussion:

$$
\begin{aligned}
\zeta_{t}= & -\left(u \zeta_{x}+v \zeta_{y}\right)-w \zeta_{z}-(f+\zeta)\left(u_{x}+v_{y}\right) \\
& -\left(\Theta_{x} \pi_{y}-\Theta_{y} \pi_{x}\right)-\left(w_{x} v_{z}-w_{y} u_{z}\right)+\left(T y_{x}-T x_{y}\right)
\end{aligned}
$$

where ()$_{x} \equiv \partial() / \partial x$, etc. The first two terms on the right hand side are the horizontal and vertical vorticity advection, the third term is the 'divergence' term. 

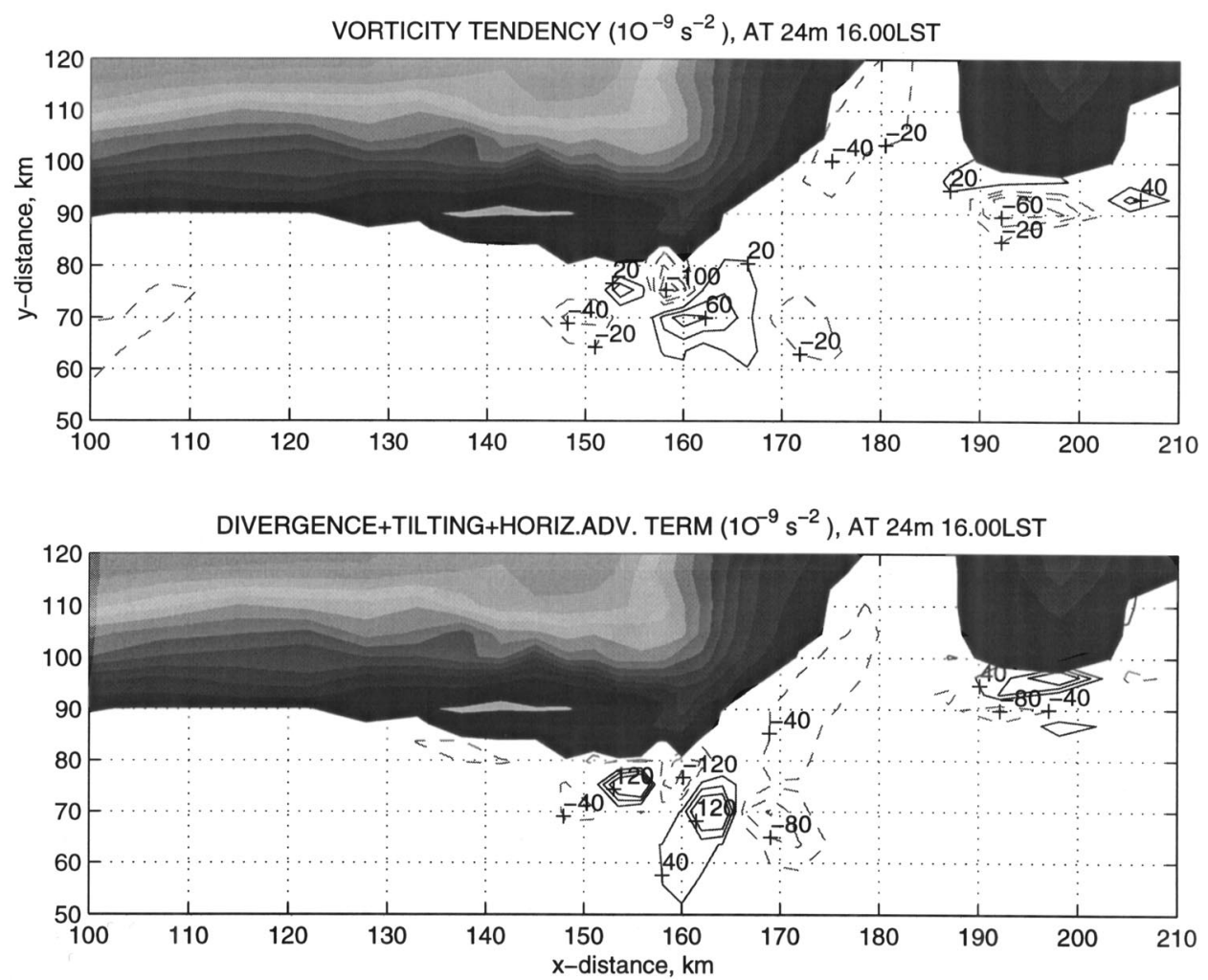

Figure 10. Vorticity tendency at $24 \mathrm{~m}$ over the sea for the northerly case at $1600 \mathrm{LST}$, just before the vorticity extreme values are obtained (upper panel). The three principal terms: 'divergence', 'tilting' and horizontal advection, added together largely govern the eddy structure (lower panel).

The fourth is the 'solenoidal' term ( $\pi$ is the Exner function), the fifth term is the 'tilting' term and the sixth term is the turbulence term ( $T x$ and $T y$ are the components of the subgrid stress terms in the $x$ and $y$ direction, respectively). Figure 10 shows vorticity tendency at $24 \mathrm{~m}$ and $1600 \mathrm{LST}$ (the upper panel). The evolution of vorticity indicates that the eddy pattern is mainly governed among three dominant terms: the 'tilting', 'divergence' and horizontal advection terms whose sum is shown in the lower panel of Figure 10. Most of the total $\zeta_{t}$ structure in Figure 10 (upper) is amplified sub-structure of the related dominating terms (lower). The three-way balance is rather delicate and it seems to be occasionally interrupted by turbulence.

The 'tilting' term is due to the strait's low-level coastal jet (large, negative $\partial v / \partial z$ ), related negative $w$, and differential vertical velocities crossing the strait (sufficient $\partial w / \partial x<0$ ). It converts horizontal into vertical vorticity $\zeta$ and works in concert with the sea-breeze type of perturbation (i.e. the diurnal heating cycle near coastlines) that enhances locally positive $w$. Hence, $\left(\zeta_{t}\right)_{\text {TILT }} \approx-w_{x} v_{z}$ determines anti-cyclonic evolution at the southern Kalmar coast and cyclonic development at 
the Öland tip. The 'divergence' term produces large positive $\zeta$ downwind from the coastline tips. There the flow converges, and in a combination with an average positive absolute vorticity, creates cyclonic flow (quite asymmetric here as the absolute vorticity varies significantly between the two eddies). The horizontal advection term plays a multiple role in transporting $\zeta$ between the two other major terms, bringing information offshore from the solenoidal term localized at the coastline, and advecting subgrid-scale turbulent effects. These subgrid stresses, creating and/or destroying $\zeta$ rapidly, redistribute $\zeta$ in the mean. It is firstly the turbulence term that accounts for the rest of $\zeta_{t}$; it mostly modulates the $\zeta_{t}$ amplitude. The 'solenoidal' term is important only near the coastline where baroclinicity sets in, but it already decays at this part of the day; nonetheless, baroclinicity was essential to initiate the significant tilting term (acting on the $w_{x}$ factor). Because the interplay among the three governing terms is sensitive, the production and subsequent transport of $\zeta$ is delicate and rather short lived.

The eddy structure is a transient mesoscale response to an interaction among the sea-breeze type of perturbation, the coastline shape, and the background flow. More simply, the eddy pattern forms as a reaction of the ambient flow to the assigned $\Delta T(t)$ distribution, and the coastal geometry. Removing the terrain showed that the coastal terrain elevations play a minor role in the eddy dynamics (which is not true for a strongly sheared background flow). This is the only distinctive case in this study in which the elevations were unimportant. For a stronger northerly background wind $\left(V \leq-10 \mathrm{~m} \mathrm{~s}^{-1}\right)$, the offshore eddies do not occur even though a notable perturbation in the flow remains. Also, another type of flow occurs for a weaker northerly background wind $\left(V \approx-4 \mathrm{~m} \mathrm{~s}^{-1}\right)$.

\section{Conclusions}

Small-scale variability of the coastal boundary layer is addressed in this study. The area of interest is the southwest segment of the Baltic sea where the 3D meso- $\gamma$ scale model is employed (Figure 1). This study follows a campaign where smallscale diversities in the coastal ABL are observed (Tjernström, 1991), and recently modeled as a case study (Tjernström and Grisogono, 1996) and a surface parameter sensitivity test (Grisogono and Tjernström, 1996). To excite various mesoscale flow regimes, the four principal wind directions are chosen as the only varying parameter (Table I). The geostrophic wind speed is always set to $8 \mathrm{~m} \mathrm{~s}^{-1}$ and the initial stratification is $\partial \Theta / \partial z \approx 4 \mathrm{~K} \mathrm{~km}^{-1}$. The most intriguing features from the four independent simulations are presented. Absence of a homogeneous, isotropic coastal ABL is revealed. Hence, measurement representativity is limited and sampling criteria for the data may be easily violated in the coastal ABL. This type of modeling appears as a useful tool in planning and analyzing observations in terms of case-study modeling, various parameter sensitivity tests, and providing an in-depth quantitative analysis of the simulated processes. 
Particular findings of the simulations presented are the following. Coastal drainage flows occur and oppose the background wind while interacting with a low-level coastal jet. On the contrary, the sea-breeze flow does not occur against this geostrophic wind, but other mesoscale responses arise (an eddy pattern in 3D, a coastal jet in 2D with a sea breeze located offshore, etc.). In other words, the drainage flow appears to be more robust to an opposing flow than the sea breeze. The terrain, although moderate, and the coastline geometry imposing the spatial distribution of the land-sea temperature contrast $\Delta T(t)$ significantly affect the flow. This necessitates an inclusion of 3D effects. Usually the coastal jets first occur during nighttime; they vary in position and intensity, which dictates the degree of interaction with the downslope flow beneath. The sea-breeze flows also show a diverse appearance. The analyzed sea breeze displays an irregular behaviour being first promoted, then suppressed at the coastline, and finally penetrating rapidly inland. The sea breeze constrained at the coast manifests shear-driven instabilities which together with turbulent drag retards the sea breeze. The coastal terrain, the ambient flow and the convective ABL (usually with substantial shear) effectively obstruct the sea-breeze propagation since they provide an excess of compensatory flow. Mesoscale transient eddies form downwind from the most substantial coastline changes and tips as a result of an interaction among the diurnal heating cycle over land surfaces, the coastline geometry, and the background flow. The eddy pattern at the strait exit follows after the coastal jet maximum in the strait. A vorticity analysis shows a delicate balance among three governing effects ('tilting', 'divergence' and horizontal advection) thus emphasizing the eddies' transience. Furthermore, the coastal MABL extends from $20 \mathrm{~km}$ to slightly over $100 \mathrm{~km}$ offshore depending on the $\Delta T$, the large-scale airflow and coastal configuration; this is in a qualitative agreement with the Rossby radius of deformation.

\section{Acknowledgements}

This work was supported by the Swedish Natural Research Council (NFR) under contracts: G-GU 01775-309 and G-GU 01775-308. We are grateful to Drs Leif Enger and Gunilla Svensson for valuable discussions and input.

\section{References}

Andrén, A.: 1990, 'Evaluation of a Turbulence Closure Scheme Suitable for Air-Pollution Applications', J. Appl. Meteorol. 29, 224-239.

Arritt, R. W.: 1989, 'Numerical Simulations of the Offshore Extent of Sea Breezes', Quart. J. Roy. Meteorol. Soc. 115, 547-570.

Arritt, R. W.: 1993, 'Effects of the Large-Scale Flow on Characteristics Features of the Sea Breeze', J. Appl. Meteorol. 32, 116-125. 
Arritt, R. W. and Physick, W. L.: 1989, 'Formulation of the Internal Boundary Layer in a Mesoscale Model. II. Simulations with a Level-2.5 Turbulence Closure', Boundary-Layer Meteorol. 49, 411-416.

Banta, R. M., Olivier, L. D., and Levison, D. H.: 1993, 'Evolution of the Monterey Bay Sea-Breeze Layer as Observed by Pulsed Doppler Lidar', J. Atmos. Sci. 50, 3959-3982.

Berger, B. W. and Grisogono, B.: 1998, 'The Baroclinic, Variable Eddy Viscosity Ekman Layer. An Approximate Analytical Solution', accepted by Boundary-Layer Meteorol.

Barthelmie, R. J., Grisogono, B., and Pryor, S. C.: 1996, 'Observations and Simulations of NearSurface Diurnal Cycles of Wind Speeds Over Land and Sea', J. Geophys. Res. 101, 2132721337.

Bluestein, H. B.: 1986, 'Fronts and Jet Streaks: A Theoretical Perspective', in P. S. Ray (ed.), Mesoscale Meteorology and Forecasting, AMS, Boston, pp. 173-215.

Brümmer, B., Hennemuth, B., Rhodin, A., and Thiemann, S.: 1995, 'Interaction of a Cold Font with a Sea-Breeze Front. Observations', Tellus 47A, 383-402.

Dalu, G. A. and Pielke, R. A.: 1989, 'An Analytical Study of the Sea Breeze', J. Atmos. Sci. 46, $1815-1825$.

Enger, L.: 1986, 'A Higher Order Closure Model Applied to Dispersion in a Convective PBL', Atmos. Environ. 20, 879-894.

Enger, L.: 1990, 'Simulation of Dispersion in Moderately Complex Terrain - Part A. The Fluid Dynamics Model', Atmos. Environ. 24A, 2431-2446.

Enger, L. and Tjernström, M.: 1991, 'Estimating the Effects on the Regional Precipitation Climate in a Semiarid Region Caused by an Artificial Lake using a Mesoscale Model', J. Appl. Meteorol. 30, 227-250.

Enger, L., Koračin, D., and Yang, X.: 1993, 'A Numerical Study of Boundary-Layer Dynamics in a Mountain Valley. Part 1. Model Validation and Sensitivity Experiments', Boundary-Layer Meteorol. 66, 357-394.

Enger, L. and Grisogono, B.: 1998: 'The Response of Bora-Type Flow to Sea Surface Temperature', Quart. J. Roy. Meteorol. Soc. In Press.

Feliks, Y.: 1988, 'The Sea-Breeze Front Analytical Model', J. Atmos. Sci. 45, 1030-1038.

Finkele, K., Hacker, J. M., Kraus, H., and Byron-Scott, R. A. D.: 1995, 'A Complete Sea-Breeze Circulation Cell Derived From Aircraft Observations', Boundary-Layer Meteorol. 73, 299-317.

Gill, A. E.: 1982, Atmosphere-Ocean Dynamics, Academic Press, New York, pp. 299-300.

Grisogono, B.: 1995, 'Wave-Drag Effects in a Mesoscale Model with a Higher-Order Closure Turbulence Scheme', J. Appl. Meteorol. 34, 941-954.

Grisogono, B. and Tjernström, M.: 1996, 'Thermal Mesoscale Circulations on the Baltic Coast. Part II: Perturbation of Surface Parameters', J. Geophys. Res. 101, 18999-19012.

Holland, G. J. and McBride, J. L.: 1989, 'Quasi-Trajectory Analysis of a Sea-Breeze Front', Quart. J. Roy. Meteorol. Soc. 115, 571-580.

Holmgren, P.: 1995, 'An Advection Algorithm and an Atmospheric Airflow Application', J. Com. Phys. 115, 27-42.

Kessler, R. C. and Douglas, S. G.: 1991, 'A Numerical Study of Mesoscale Eddy Development over the Santa Barbara Channel', J. Appl. Meteorol. 30, 633-651.

McCumber, M. C. and Pielke, R. A.: 1981, 'Simulation of the Effects of Surface Fluxes of Heat and Moisture in a Mesoscale Numerical Model. Part I: Soil layer', J. Geophys. Res. 86, 9929-9938.

Manins, P. C. and Sawford, B. L.: 1979, 'Katabatic Einds: A Field Case Study', Quart. J. Roy. Meteorol. Soc. 105, 1011-1025.

Pielke, R. A.: 1984, Mesoscale Numerical Modeling, Academic Press. 612 pp.

Rhodin, A.: 1995, 'Interaction of a Cold Front with a Sea-Breeze Front. Numerical Simulations', Tellus 47A, 403-420.

Rotunno, R.: 1983, 'On the Linear Theory of Land and Sea-Breeze', J. Atmos. Sci. 40, 1999-2009. 
Sha, W. and Kawamura, T.: 1991, 'A Numerical Study on Sea/Land Breezes as a Gravity Current: Kelvin-Helmholtz Billows and Inland Penetration of the Sea-Breeze Front', J. Atmos. Sci. 48, 1649-1665.

Smedman, A.-S., Tjernström, M., and Högström, U.: 1993, 'Analysis of the Turbulence Structure of a Marine Low Level Jet', Boundary-Layer Meteorol. 66, 105-126.

Smedman, A.-S., Bergström, H., and Grisogono, B.: 1997, 'Evolution of Stable Internal Boundary Layers Over a Cold Sea', J. Geophys. Res. 102, 1091-1099.

Svensson, G.: 1996a, 'A Numerical Model for Chemical and Meteorological Processes in the Atmospheric Boundary Layer. Part I: A Model Description and a Parameter Study', J. Appl. Meteorol. 35, 939-954.

Svensson, G.: 1996b, 'A Numerical Model for Chemical and Meteorological Processes in the Atmospheric Boundary Layer. Part II: A Case Study of the Air Quality Situation in Athens, Greece', J. Appl. Meteorol. 35, 955-973.

Tjernström, M.: 1987, 'A Study of Flow Over Complex Terrain Using a Three-Dimensional Model. A Preliminary Model Evaluation Focusing on Stratus and Fog', Annales Geophysica 5b, 469-486.

Tjernström, M.: 1988, 'Numerical Simulations of Stratiform Boundary-Layer Clouds on the Meso$\gamma$-scale. Part II: The Influence of a Step Change in Surface Roughness and Surface Temperature', Boundary-Layer Meteorol. 44, 207-230.

Tjernström, M.: 1991, 'Airborne Observations of Thermal Mesoscale Circulations in the Coastal Marine Boundary Layer', J. Geophys. Res. 96, 20499-20520.

Tjernström, M., Enger, L., and Andrén, A.: 1988, 'A Three-Dimensional Numerical Model for Studies of Atmospheric Flows on the Meso- $\gamma$ Scale', J. Theor. Appl. Mech. 7, 167-194.

Tjernström, M. and Smedman, A.-S.: 1993, 'The Vertical Structure of the Coastal Marine Atmospheric Boundary Layer', J. Geophys. Res. 98, 4809-4826.

Tjernström, M. and Grisogono, B.: 1996, 'Thermal Mesoscale Circulations on the Baltic Coast. Part I: A Numerical Case Study', J. Geophys. Res. 101, 18979-18997.

Wilczak, J. M, Dabberdt, W. F., and Kropfli, R. A.: 1991, 'Observations and Numerical Model Simulations of the Atmospheric Boundary Layer in the Santa Barbara Coastal Region', J. Appl. Meteorol. 30, 652-673.

Winant, C. D., Dorman, C. E., Friehe, C. A., and Beardsley, R. C.: 1988, 'The Marine Layer Off Northern California: An Example of Supercritical Channel Flow', J. Atmos. Sci. 45, 3588-3605.

Yang, X.: 1991, 'A Study of Nonhydrostatic Effects in Idealized Sea Breeze Systems', BoundaryLayer Meteorol. 54, 183-208.

Zhong, S. and Takle, E. S.: 1993, 'The Effects of Large-Scale Winds on the Sea-Breeze Circulations in an Area on Complex Coastal Heating', J. Appl. Meteorol. 32, 1181-1195. 